\title{
Erratum: Measurement of Body-Centered-Cubic Aluminum at 475 GPa [Phys. Rev. Lett. 119, 175702 (2017)]
}

D. N. Polsin, D. E. Fratanduono, J. R. Rygg, A. Lazicki, R. F. Smith, J. H. Eggert, M. C. Gregor, B. H. Henderson, J. A. Delettrez, R. G. Kraus, P. M. Celliers, F. Coppari, D. C. Swift, C. A. McCoy, C. T. Seagle, J.-P. Davis, S. J. Burns, G. W. Collins, and T. R. Boehly

(ه) (Received 8 December 2017; published 10 January 2018)

DOI: 10.1103/PhysRevLett.120.029902

The sentence in the fifth paragraph on pg. 2 of the manuscript that reads

— "The data are compared to the Kerley 3700 isentrope [24]..."

should read

—"The data are compared to the Kerley 3700 isentrope [26]...."

[24] Y. B. Kudasov, O. M. Surdin, A. S. Korshunov, V. N. Pavlov, N. V. Frolova, and R. S. Kuzin, J. Exp. Theor. Phys. 117, 664 (2013).

[26] G. I. Kerley, Int. J. Impact Eng. 5, 441 (1987). 